effects, as Beaconsfield and his colleagues maintain, surely the kind of evaluation of them which is required is different from that which we read about? What is the type of testing for drugs taken in the long term that they have mentioned $?^{3} \quad$ Has it been spelt out anywhere and I have missed it? If new testing is required, whose responsibility is it to see that it is done? And in which way

can this help to improve the present pill ?I am, etc.,

Pinner, Middx

\title{
R. Grenville-Mathers.
}

REFERENCES

Beaconsfield, P., Abrams, M. E., Ginsburg, J., and Rainsbury, R., Lancet, 1968, 2, 832 .

Daily Telegraph, 10 October 1968 Beaconsfield, P., and Ginsburg, J., Lancet, 1968.
B. 992.

\section{Long-acting Synthetic Corticotrophin in Dermatology}

SIR,-The latest paper by Dr. A. H. El-Shaboury (14 September, p. 653) showing that the long-acting synthetic corticotrophin Synacthen Depot is safe in patients sensitive to animal corticotrophin prompts me to describe our experience with its use in certain skin diseases.

Our interest was aroused by the work of Besser et al. ${ }^{1}$ in this hospital, who showed

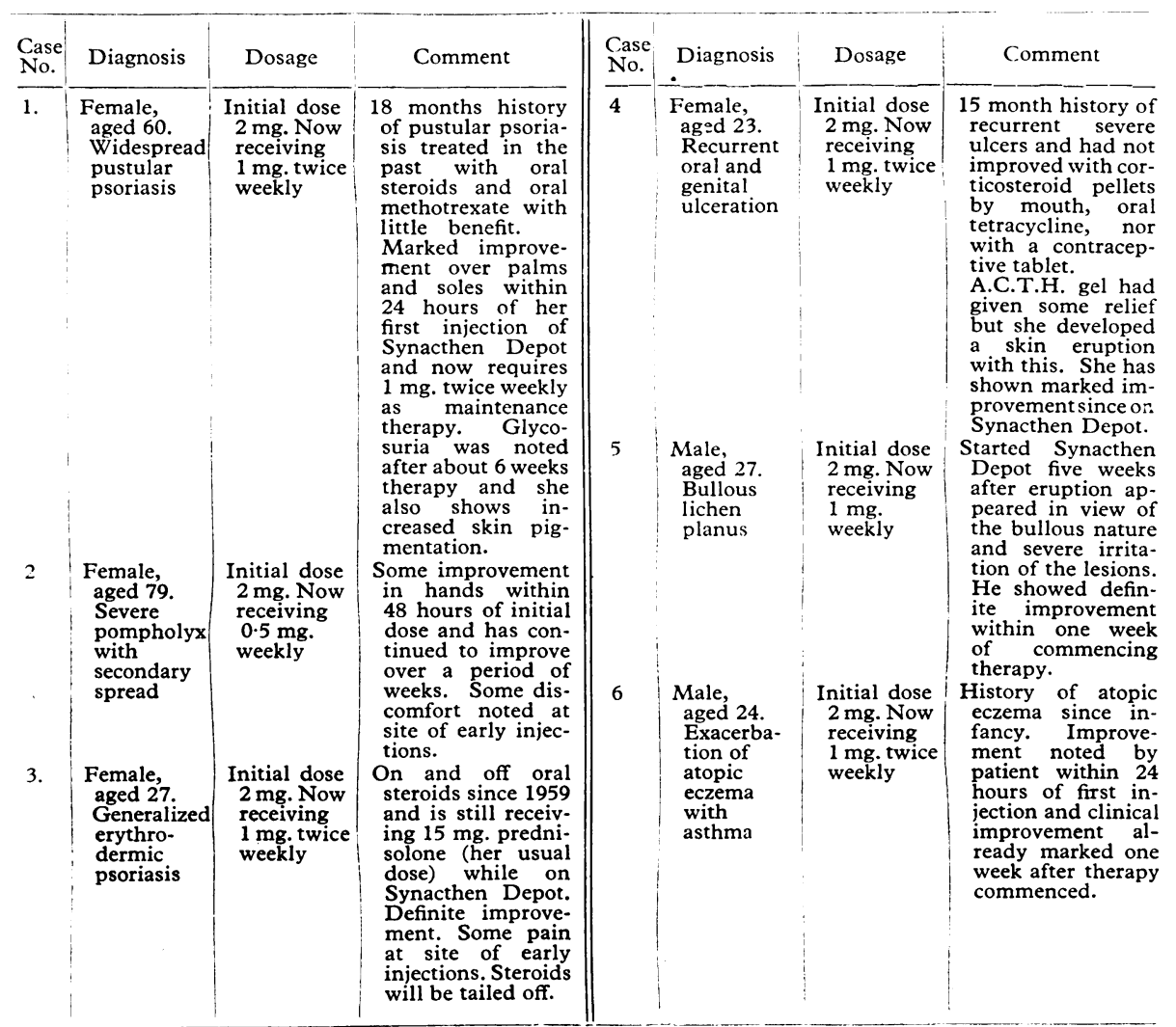

that it had equivalent potency but a longer duration of action than corticotrophin gel. This was confirmed by Dr. J. K. Nelson and colleagues (2 March, p. 557). Increasing the dose extends the duration of action. Our dosage has, therefore, varied between 0.5 and $2 \mathrm{mg}$. and our usual regimen has been $1 \mathrm{mg}$. twice weekly. We naturally started with problem cases, but have been sufficiently impressed with the results over the last few months that we are extending its use. A fuller publication is in prospect, but meanwhile the Table shows the results so far in the first six patients treated.

\section{Duodenal Haematoma}

SIR,-I was interested to read the case I would agree entirely that this is a recogreport on duodenal haematoma by Dr. S. nizable clinical entity, which may be diagnosed Mindel and Dr. Louis Kreel (28 September, radiologically. The history of a blow in the p. 785). I have seen three such $\operatorname{cases}^{1}$ and epigastrum followed 24 hours later by symp- toms suggestive of pyloric obstruction is typical. ${ }^{2}$ However, there are two points which might profitably be emphasized.

Plain radiographs of the abdomen may themselves be diagnostic of this condition, and will certainly indicate the necessity for barium meal. Gas may distend the duodenum and outline it as clearly as does barium. In one of our cases the principal features of intramural haematoma, as described by Felson and Levin, ${ }^{3}$ were clearly demonstrated in this manner. Drs. Mindel and Kreel suggest that adequate $x$-ray studies may obviate the necessity for laparotomy. There are many reports which suggest that laparotomy should be performed immediately the diagnosis of intramural haematoma is made $^{2-6}$ in order to exclude concomitant undiagnosed injury, and to avert later complications. Having successfully managed two out of three patients conservatively, I agree that operation is not mandatory. However, the injury is, of course, much more extensive than the simple term "intramural haematoma " would suggest. The patient must be kept under very close observation for many days, and if there are any doubts at all laparotomy should be performed. It is because of the extensive nature of the injury, although intramural may be the central feature, that I would prefer the more noncommittal term "duodeno-jejunal haematoma " to describe this condition.-I am, etc.,

\section{Department of Urology, \\ Newcastle General Hospital, Newcastle upon Tyne. \\ REFERENCES} D. M. Essenhigh.

'Essenhigh, D. M., and Toland, J., Brit. 7 . Radiol., 1968, 41, 349 . 1967, 54, 50. 63. 823. V., and Southwood, W. F. W., Brit. f. Surg., 1964, 51, 767

Davis, D., R., and Thomas, C. Y., Ann. Surg., Lampert, E. E. G.. Goodfellow, J., G.j’, and

SIR,-May we record another case of duodenal haematoma (28 September, p. 785) due not to trauma but to a carcinoma of the ampulla of Vater?

The patient was a female aged 52 years, who had had iaundice for four weeks, followed by abdominal pain for one week. She was admitted to this hospital after the pain became severe. She was dyspnoeic and comatose and died shortly after admission.

Necropsy revealed a large haemorrhagic sac attached to the lower border of the third and fourth parts of the duodenum, filling a large proportion of the lower abdomen. It was entirely retroperitoneal. The pancreas showed haemorrhagic inflammatory changes, blood from which had tracked into the region of the ampulla and dissected the wall of the duodenum to produce an intramural haematoma. The ampullary region was the seat of nodular ulcerated growth, sections from which showed undifferentiated carcinoma. Other necropsy findings included a neurofibromatous hamartoma of the left lobe of the liver, and partial glial stenosis of the aqueduct of Sylvius.-We are, etc.

R. R. GHose.

A. L. WELLS

Llanelli Hospital,

Llanelli, Carmarthenshire. 